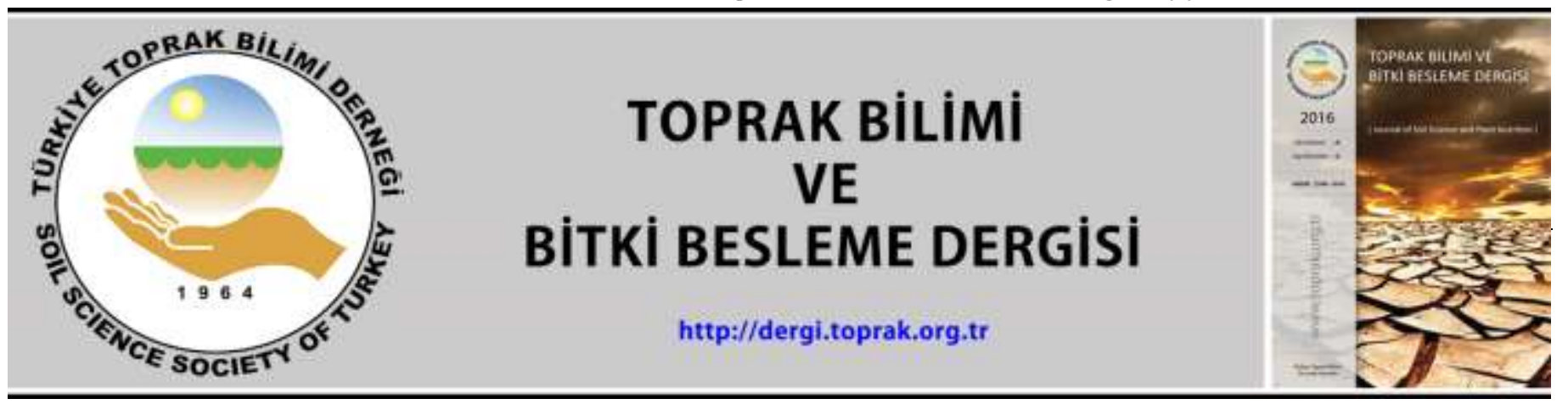

\title{
Çarşamba Ovası'nda soya yetiştirilen tarım alanlarının verimlilik durumlarının belirlenmesi
}

\author{
Nalan Kars 1, İmanverdi Ekberli 2,* \\ ${ }^{1}$ Karadeniz Tarımsal Araștırma Enstitüsü Müdürlüğü, Samsun \\ ${ }^{2}$ Ondokuz Mayıs Üniversitesi, Ziraat Fakültesi, Toprak Bilimi ve Bitki Besleme Bölümü, Samsun
}

\begin{abstract}
Özet
$\mathrm{Bu}$ araştırma, Çarşamba Ovası'nda geleneksel toprak işleme yöntemleriyle soya bitkisi yetiştirilen tarım topraklarının verimlilik durumunu belirlemek amacıyla yürütülmüștür. $\mathrm{Bu}$ amaçla, ovada yer alan 20 köyde soya tarımı yaplan arazilerden toprak örnekleri alınmış ve bu örneklerin bazı fiziksel ve kimyasal özellikleri belirlenmiştir. Ayrıca, aynı arazilerden bitki örnekleri alınarak bazı agronomik unsurları belirlenmiștir. Araştırma iki yıl süre ile aynı arazilerde yürütülmüștür. Araştırma sonuçlarına göre, topraklar genellikle kil ve killi tın bünyeye sahip, hacim ağırlığı değerleri 1.0-1.3 g cm-3 (\%62.5'i), tarla kapasitesi değerleri \%30-\%40 (\%55'i) arasında, nötr ve hafif alkalin reaksiyonlu, tuzsuz, kireçsiz ve orta kireçli olup, organik madde miktarı orta ve iyi (\%62.5'i) seviyede saptanmıştır. Toprakların azot miktarı orta ve fazla (\%44.5'i), fosfor miktarı az ve orta (\%57.5'i), potasyum miktarı orta (\%67.5'i), katyon değişim kapasitesi ise çok yüksek (\%65'i) olarak belirlenmiştir. Toprakların demir içeriği (\%65'i) yüksek, mangan içeriği düşük (\%85’i), bakır içeriği (\%92.5'i) çok yüksek, çinko içeriği ise çok düşük (\%90'i) düzeyde bulunmuştur. Soya bitkisinin ortalama bitki boyu, bin tane ağırlı̆̆ı ve tane verim değerleri sırasıyla; $103.31 \mathrm{~cm}, 200.54 \mathrm{~g}$ ve $455.87 \mathrm{~kg}$ da-1 olduğu saptanmıştır. Araştırma topraklarının organik madde, azot ve fosfor içerikleri genel olarak düşük olduğundan, topraklara organik, azotlu ve fosforlu gübrelerin uygulanması ile verimde artış sağlanabilir.
\end{abstract}

Anahtar Kelimeler: Çarşamba ovası, fiziksel ve kimyasal özellikler, frekans dağılımı, glycine max l. merill.

\section{Determination of productivity status of soybean cultivated fields in Çarşamba Plain}

\begin{abstract}
This research was carried out in order to determine the productivity status of agricultural lands where soybean plants were grown by traditional soil cultivation methods in Çarşamba Plain. For this purpose, soil samples were taken from the lands where soybean cultivation was carried out in 20 villages on the plain and their some physical and chemical properties were determined. In addition, some agronomic components were determined by taking plant samples from the same land. The research was executed on the same lands for two years. According to the research results, the soils usually were determined to have clay and clay loam, bulk density values $1.0-1.3 \mathrm{~g} \mathrm{~cm}-3(62.5 \%)$, field capacity values of $55 \%$ were found as $30-40 \%$, neutral and slightly alkaline reaction, salt-free, limeless and medium-lime, organic matter was determined at a moderate and good level (62.5\%). The nitrogen content of the soils was medium and high (44.5\%), the amount of phosphorus was low and medium (57.5\%), the amount of potassium was medium (67.5\%), and the cation exchange capacity was very high (65\%). Content of iron in the soils was high (65\%), content of manganese was low (85\%), content of copper was very high (92.5\%), and content of zinc was very low (90\%). The average plant height, thousand seed weight and seed yield values of soybean were determined as $103.31 \mathrm{~cm}, 200.54 \mathrm{~g}$ and $455.87 \mathrm{~kg}$ da-1, respectively. Since the organic matter, nitrogen and phosphorus contents of the research soils are generally low, the yield will be increased by applying organic, nitrogenous and phosphorous fertilizers to the soils.
\end{abstract}

Keywords: Çarşamba plain, frequency distribution, physical and chemical properties, glycine max l. merill.

(C) 2020 Türkiye Toprak Bilimi Derneği. Her Hakkı Saklıdır

\section{Giriş}

Dünyanın en değerli sanayi bitkileri arasında yer alan soya fasulyesi (glycine max l. merill.) tanesinde bulunan ortalama \%18-20 yağ, \%40 protein, \%30 karbonhidrat, \%5 mineral madde (Ca, Fe, Zn) ve çok sayıda vitamin $\left(A, B_{1}, B_{2}, C, D\right.$, E ve $\left.K\right)$ ile bitkisel yağ sanayisi ve gıda endüstrisinin; küspesi ile de hayvan besiciliğinin önemli bir ham maddesidir (Arıoğlu, 2000; Temperly ve Borges, 2006). Soya fasülyesi tıbbi amaçla da kullanılmakta, yaklaşık 4500 yıldan beri birçok Uzakdoğu ülkelerinin (Çin, Kore, Japonya) gıda

\footnotetext{
* Sorumlu yazar:

Tel. : $\quad 03623121919$

E-posta : iman@omu.edu.tr
}

Geliș Tarihi

Kabul Tarihi
e-ISSN

DOI : $10.33409 /$ tbbbd.756822 
beslenmesinde faydalanıldığı bilinmektedir. Baklagil türlerinden olan soya bitkisi, biyolojik azot fiksasyonu ile yüksek miktarlarda azotu fikse ederek toprak verimliliğini iyileștirmede önemli bir rol oynamaktadır. Ülkemiz iklim ve toprak koşulları dikkate alındığında, yağlı tohumlu bitkilerin üretiminde önemli bir potansiyele sahiptir. Soya fasülyesinin tarımı ilk olarak Karadeniz Bölgesinde 1940 yıllında yapılmış ve 1957 yılında Ordu ilinde soya yağı fabrikası (Sümerbank) açılmıştır. Bugün ise soya tarımının en çok yapıldığı iller Adana, Mersin, Osmaniye ve Samsun'dur. (Öner, 2006; Coşkan ve ark., 2009). Ülkemizde soya bitkisinin toplam ekim alanı 38180 ha, üretimi 165000 ton, verimi ise $432 \mathrm{~kg} \mathrm{da}^{-1}$ olmaktadır. Karadeniz bölgesinde en önemli tarımsal potansiyele sahip olan Çarşamba Ovası'nda soya fasülyesinin ekim alanı 659 ha, üretimi 2796 ton, verimi ise $424 \mathrm{~kg} \mathrm{da}^{-1}{ }^{\prime} \mathrm{d}$ ır (Anonim, 2016).

Soya bitkisi yetiştirilen toprakların verimlilik durumunun (fiziksel ve kimyasal özelliklerinin) saptanması, bu yöntemlerin belirlenmesi için gerekli aşamalardan biridir. Aynı zamanda, toprakların uzun yıllar verimli ve üretken bir șekilde kullanımını hedefleyen sürdürülebilir tarım yaklașımları önemini giderek artırmıștır. Virk ve ark. (2017) tarafından yapılan bir çalışmada, \%79.5 kum, \%8.2 silt, \%13.1 kil, 7.4 pH, \%0.28 organik karbon, $130.3 \mathrm{~kg} \mathrm{ha}^{-1}$ alınabilir azot, $18.3 \mathrm{~kg} \mathrm{ha}^{-1}$ alınabilir fosfor ve $159.4 \mathrm{~kg} \mathrm{ha}^{-1}$ alınabilir potasyum içeren topraklarda soya bitkisinden iyi verim elde edilmesi için, yüzeysel toprak işleme, gübreleme gibi tarımsal işlemlerin gerekli olduğu vurgulanmıştır. Glifosat ve çinko uygulamasının toprak verimliliği, soya verimi ve diğer verim unsurları, besin elementleri durumu üzerine etkisinin belirlenmesine ait yapilan bir çalışmada, uygulama yapılmamış araştırma toprağında $\mathrm{P}, \mathrm{K}, \mathrm{Ca}, \mathrm{Mg}, \mathrm{Cu}, \mathrm{Mn}$ miktarları sırasıyla $20.6 \mathrm{mg} \mathrm{kg}-1$; $0.12 \mathrm{cmol}$ $\mathrm{kg}^{-1} ; 1.55 \mathrm{cmol} \mathrm{kg}^{-1} ; 0.78 \mathrm{cmol} \mathrm{kg}^{-1} ; 0.68 \mathrm{mg} \mathrm{kg}^{-1} ; 23.75 \mathrm{mg} \mathrm{kg}{ }^{-1}$ olarak bulunmuş ve bu özelliklerin bölgesel olarak değişim gösterdiği saptanmıştır (Moreira ve ark., 2016). Besin maddelerinin olası eksikliği, diğer toprak özelliklerinin optimum düzeyde olmasına rağmen soya verimini olumsuz yönde etkilemektedir (Aulakh ve ark., 2003; Moreira ve ark., 2017). Soya bitkisinde demir noksanlığının toprak özellikleri ile ilişkisinin beirlenmesine ait 60 lokasyonda yürütülen bir araştırmada, yaprakların klorotik olması

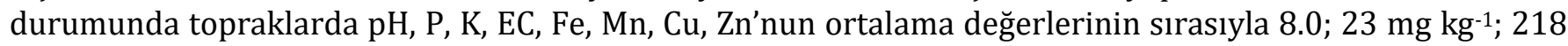
$\mathrm{mg} \mathrm{kg}{ }^{-1} ; 0.92 \mathrm{dS} \mathrm{m}^{-1} ; 8.46 \mathrm{mg} \mathrm{kg}^{-1} ; 8.61 \mathrm{mg} \mathrm{kg}^{-1} ; 1.26 \mathrm{mg} \mathrm{kg}^{-1} ; 1.94 \mathrm{mg} \mathrm{kg}^{-1}$, yaprakların orta derecede klorotik olması durumunda 8.0; $21 \mathrm{mg} \mathrm{kg}^{-1} ; 220 \mathrm{mg} \mathrm{kg}^{-1} ; 0.68 \mathrm{dS} \mathrm{m}^{-1} ; 8.65 \mathrm{mg} \mathrm{kg}^{-1} ; 9.06 \mathrm{mg} \mathrm{kg}^{-1} ; 1.24 \mathrm{mg} \mathrm{kg}-1 ; 1.94$ mg kg-1, yaprakların sağlıklı olması durumunda ise $8.0 ; 24 \mathrm{mg} \mathrm{kg}^{-1} ; 228 \mathrm{mg} \mathrm{kg}^{-1} ; 0.52 \mathrm{dS} \mathrm{m}^{-1} ; 11.8 \mathrm{mg} \mathrm{kg}^{-1}$; $9.66 \mathrm{mg} \mathrm{kg}^{-1} ; 1.29 \mathrm{mg} \mathrm{kg}^{-1} ; 2.1 \mathrm{mg} \mathrm{kg}^{-1}$ olduğu belirlenmiştir (Hansen ve ark., 2004). Kitou ve Yoshida (1994) tarafından bitki kalıntıları ile yapılan malçlamanın, soya bitkisinin gelişimi ve toprağın kimyasal özellikleri üzerine etkisinin incelenmesine ait bir araştırmada ise, EC, C, N, K, Ca, Mg içerikleri sırasıyla $0.13 \mathrm{dS} \mathrm{m}^{-1}, 13.4$ $\mathrm{g} \mathrm{kg}^{-1}, 1.0 \mathrm{~g} \mathrm{~kg}^{-1}, 0.42 \mathrm{cmol} \mathrm{kg}^{-1}, 1.06 \mathrm{cmol} \mathrm{kg}^{-1}, 0.20 \mathrm{cmol} \mathrm{kg}^{-1}$ olan killi tınlı bir toprak kullanılmıștır. Soya fasulyesinin (glisin max l. merril) kritik büyüme aşamalarına (çiçeklenme/bakla sayısı) etki yapan faktörlerin belirlenmesine ait bir araștırmada (Harasim ve ark., 2016), deneyin başlangıcında topraktaki humus, P, K, Mg miktarlarının sırasıyla $16.9 \mathrm{~g} \mathrm{~kg}^{-1}$; $14.4 \mathrm{mg} 100 \mathrm{~g} \mathrm{~g}^{-1} ; 33.7 \mathrm{mg} 100 \mathrm{~g}^{-1} ; 5.9 \mathrm{mg} 100 \mathrm{~g}^{-1}$ olduğu belirlenmiştir. Bir çok araştırmacılar tarafından (Sato ve ark., 2003; Brye ve ark., 2007; Ngakou ve ark., 2008; Verkler ve ark., 2009; Fageria ve ark., 2014; Moreira ve ark., 2018; Gavili ve ark., 2019) soya bitkisinin veriminin ve verim kalitesinin yükseltilmesinde çeşitli tarımsal yöntemlerin uygulanmasının toprakların fiziksel ve kimyasal özelliklerine önemli düzeyde bağlı olduğu gösterilmiştir. Adams ve ark. (2017)'e göre de, yüksek verimli soya fasulyesi üretimi ile ilişkili toprak özelliklerinin belirlenmesi toprak ortamının iyi anlaşılması için gereklidir.

Yoğun tarımsal faaliyetler ve artan mekanizasyon toprakların fiziksel ve mekanik özelliklerinde bozulmalara sebep olmakta ve ayrıca organik gübre kullanımının yeterli olmaması ve kimyasal gübrelerin aşırı kullanılması da bozulmayı hızlandırmaktadır. Amaç dıșı kullanımı sonucunda azalan tarım alanlarımızda sürdürülebilir bir üretim yapabilmek ve toprakların optimum düzeyde kullanılması için tarım toprakların fiziksel ve kimyasal özelliklerinin araştırılmasıyla bu özelliklere uygun amenajman önlemlerinin alınması zorunluluk haline gelmiştir. Her türlü tarımsal üretimin temelini oluşturan toprakların etkin ve sürdürülebilir kullanımı için temel özelliklerinin bilinmesi gerekmektedir. Sürdürülebilir tarım; toprağın fiziksel, kimyasal ve biyolojik özelliklerini iyileştirmek, geliştirmek ve korumakla mümkün olmaktadır. Tarım topraklarının temel özelliklerinin belirlenerek, bu özellikler doğrultusunda kullanım amacına uygun olarak değerlendirilmesi ve herhangi bir kullanım altında davranışın tahmin edilmesi günümüz tarımı için bir ihtiyaç olmaktadır (Ekberli ve Kerimova, 2005; Tümsavaş ve Aksoy, 2009; Gülser ve ark., 2010; Hossain ve ark., 2015; Gülser, 2016; Gülser ve ark., 2016; Dengiz ve Ekberli, 2017; Lipiec ve Usowicz, 2018; Kars ve Ekberli, 2019a; 2019b). Bölgelerin iklimsel, bitkisel ve toprak özellikleri açısından farklılık göstermesi ve toprak özelliklerinin bölgeye özgü özelliklerle etkileşimi, verimlilik çalısmalarının yöresel yapılmasını gerektirmektedir (Kırmızı ve Tüfekçi, 1993). Van ili Bayramlı köyü bağ alanlarının bazı toprak özelliklerinin belirlendiği bir çalışmada, toprakların nötr ve akali reaksiyonlu, tuzsuz, kireçsiz, orta ve yeterli düzeyde 
organik madde içeriğine sahip olduğu; toprakların \%47.5'inin tınlı kum, \%45'inin kumlu tın ve \%7.5'inin kumlu olduğu bildirilmiştir (Sancan ve Karaca, 2017). Taban ve ark. (2004) tarım yapılan alanlardan verimlilik durumunu belirlemek amacıyla 40 adet toprak örneği alarak toprakların bazı fiziksel ve kimyasal özelliklerini belirlemişlerdir. Genel olarak, killitın, tın ve kumlu killitın tekstüre sahip, hafif alkali reaksiyonlu ve orta kireçli olduğu; toprakların \% 67.5'inin azot, \% 40' ının fosfor, \% 82.5'inin kükürt, \% 5'inin potasyum, \% 97.5'inin çinko ve mangan, \% 7.5'inin demir ve \% 67.5'inin bor bakımından yetersiz olduğu saptanmıştır. Bursa İlinde çeşitli ürünlerin yetiştirildiği alanlarda, toprak verimlilik durumlarını belirlemek amacı ile yapılan bir araştırmada (Başar, 2001), toplam 1018 adet toprak örneği incelemiştir. Araştırma sonuçlarına göre, toprakların \% 56.49'unun organik madde, \% 21.81'inin P ve \% 21.82'sinin K içeriklerinin düşük ve çok düşük düzeylerde olduğu bildirilmiştir. Doğu Karadeniz Bölgesindeki kırmızı-sarı podzolik toprakların temel bazı karakteristik özellikleri ve verimlilik durumunu belirlemek amacıyla 370 adet toprak örneği alınmıștır. Örneklerde yapılan bazı fiziksel ve kimyasal toprak analizleri sonucunda, topraklar genellikle killi tın, kumlu killi tın, kumlu tın ve tın tekstürlü olup, düşük $\mathrm{pH}$ değerlerine sahip olduğu, tuzluluk sorununun bulunmadığı, alınabilir P, ekstrakte edilebilir K ve Ca yönünden toprak örneklerinin çoğunluğunun yetersiz düzeyde olduğu, organik madde açısından toprakların \% 70'inin yüksek durumda olduğu belirlenmiştir (Özyazıcı ve ark., 2013). Gürbüz ve ark. (2019) Trakya topraklarının veri tabanının oluşturulması ve bazı toprak özelliklerinin inceledikleri çalışmalarında, toprakların yaklaşık, $1 / 3$ 'ünün hafif, $1 / 5^{\prime}$ inin orta ve 2/5'inin ağır bünyeli olduğunu; yaklaşık 2/5'inin asit, 1/5'inin nötr ve 2/5'inin alkalin reaksiyonlu; 3/4'ünün tuzsuz; $1 / 2$ 'sinin kireçsiz ve çok az kireçli, $1 / 5$ 'inin orta kireçli ve kireçli olduğunu bildirmişlerdir. Ayrıca, organik madde bakımından 1/5'inin çok az, 3/5'inin az, 1/5'inin ise orta ve zengin; fosfor bakımından $1 / 5^{\prime}$ inin yetersiz ve çok yetersiz, 1/5'inin çok yüksek, ekstrakte edilebilir potasyum bakımından, 1/7'sinin az, 3/5'inin yüksek ve çok yüksek sınıfında yer aldığı belirlenmiştir

$\mathrm{Bu}$ araştırmanın amacı, Samsun'un Çarşamba Ovası'nda geleneksel yöntemlerle soya yetiştirilen tarım topraklarının verimlilik durumunun ortaya konulmasıdır.

\section{Materyal ve Yöntem}

Araştırma; iki yıl süre ile Samsun ili Çarşamba Ovası'nı temsil eden 20 köyde, çiftçiler tarafından soya tarımının yapıldığı arazilerden 0-20 cm derinlikten Jackson (1962) tarafından bildirildiği şekilde her yıl için 20 toprak örneği alınarak gerçekleștirilmiştir. Aynı alanlardan bitki örneklerinin alınmasında Anonim (2013)'de gösterilen yöntem kullanılmıştır. Toprak ve bitki örneklerinin alındığı lokasyonlar Şekil 1'de gösterilmiştir.

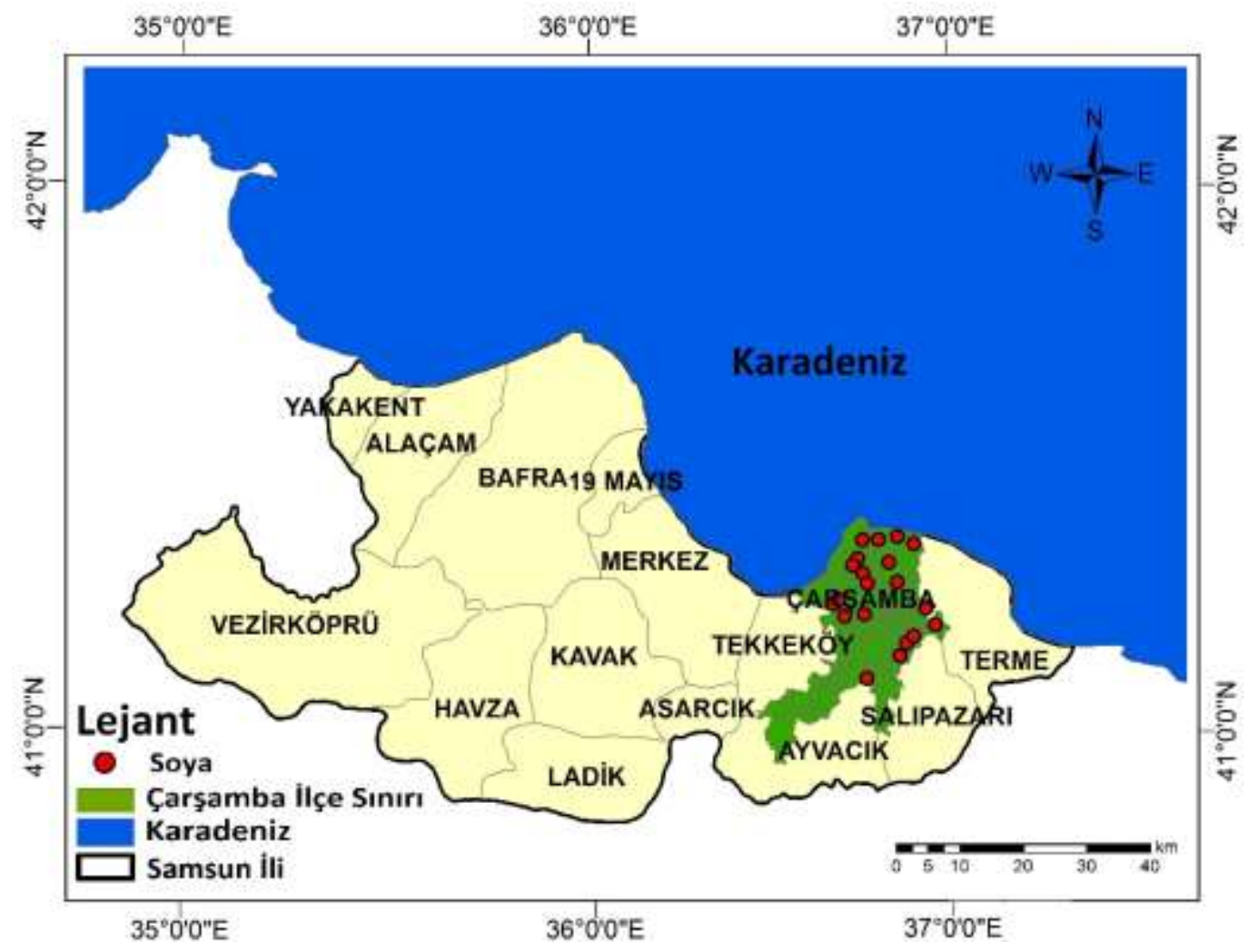

Şekil 1. Toprak ve bitki örneklerinin alındığı lokasyonlar 
Samsun ili sınırları içerisinde yer alan Çarşamba Ovası, güneyde Canik dağları ile kuzeyde ise Karadeniz ile sınırı bulunan Yeșilırmak'ın olușturduğu bir delta ovasıdır. Ova 0-50 m kotları arasında, 103.766 hektarlık bir alanı kapsamaktadır. Çarşamba Ovası doğu-batı istikametinde $65 \mathrm{~km}$, güney-kuzey istikametinde ise 35 km uzunluğa sahiptir. Ova taban arazilerinin genel eğimleri güney-kuzey istikametinde olup ortalama eğim \% 0.1'dir. Bu eğim, deniz kenarına yaklaştıkça \% 0-0.02'ye kadar düşmektedir. Yamaç arazilerde ise eğim, \% 2-40 arasında değişmektedir. Ova; bitki örtüsü yönünden çok zengin olup, 58.921 hektar tarım arazisine sahiptir. Ovada buğday bitkisi 1.700 hektar alanda yetiştirilmektedir. Ova toprakları alüviyal ve kısmen de kolüviyal (kestane rengi topraklar, gri-kestane podzolik topraklar, kahverengi orman toprakları) karakterdedir (Anonim, 1984). Ovada yıllık toplam yağış miktarı 985.9 mm olup, yıllık sıcaklık ortalaması ise $15-17^{\circ} \mathrm{C}^{\prime}$ dir (Turan ve ark., 2018).

Alınan toprak örneklerinde tekstür hidrometre yöntemiyle (Demiralay, 1993); hacim ağırlı̆̆ Demiralay (1993)'a göre; toprak reaksiyonu (pH), 1:1 oranında hazırlanan toprak-su süspansiyonunda cam elektrotlu pH metre ile (Bayraklı, 1987); elektriksel iletkenlik (EC), 1:1 oranında hazırlanan toprak-su süspansiyonunda elektriksel kondaktivite aleti ile (Richards, 1954); kireç $\left(\mathrm{CaCO}_{3}\right)$, Scheibler kalsimetresiyle volümetrik olarak (Kacar, 1994); organik madde (OM), Walkley-Black yaş yakma yöntemine göre (Kacar, 1994); toplam azot (N) Kjeldahl yaş yakma yöntemine göre (Kacar, 1994) belirlenmiştir. Toprakların yarayışlı fosfor (P) içeriği, mavi renk yöntemine göre (Olsen ve ark., 1954); değişebilir potasyum (K) ve sodyum ( $\mathrm{Na})$, toprak örneğinin $1 \mathrm{~N}$ amonyum asetat $(\mathrm{pH}=7.0)$ çözeltisi ile ekstrakte edilmesiyle, kalsiyum (Ca) ve magnezyum (Mg) 0.01M EDTA titrasyonu ile (Sağlam, 1997); katyon değişim kapasitesi (KDK), Bower yöntemine göre (U.S. Salinity Lab. Staff, 1954) alınabilir demir (Fe), bakır (Cu), mangan (Mn) ve çinko (Zn) içerikleri ise Lindsay ve Norvell (1978) tarafından bildirildiği şekli ile (0.005 M DTPA + 0.01 $\mathrm{M} \mathrm{CaCI}_{2}$ +0.1 M TEA, pH= 7.3) tespit edilmiştir. Tarla kapasitesi (TK) ve solma noktası (SN) değeri, basınçlı tabla aletinde sırasıyla $1 / 3$ atm ve 15 atm basınç altında toprak örneklerinin hidrolik denge durumuna gelmesinden sonra ağırlık esasına göre (Black, 1965); bitkiye yarayışlı su miktarı (BYS), TK ve SN arasındaki farktan hareketle hesap yolu ile belirlenmiștir. Soya bitkisinde bitki boyu (BB), bin tane ağırlığı (BTA) ve tane verimi (TV) ölçümleri, Anonim (2013) tarafından bildirilen esaslar çerçevesinde yapılmıştır.

\section{Bulgular ve Tartışma}

\section{Soya bitkisinin agronomik unsurları}

Araştırma alanında yetiştirilen soyanın bazı agronomik parametrelerine ilişkin tanımlayıcı istatistikler Çizelge 1'de verilmiştir. Çizelge 1'den görüldüğü gibi, soya bitkisinin BB, BTA ve TV değerleri sırasıyla; 88.33-127.27 cm, 164.10-242.91 g ve 280.32-593.16 $\mathrm{kg} \mathrm{da}^{-1}$ arasında değişmekte, ortalama değerleri ise sırasıyla $103.31 \mathrm{~cm}, 200.54 \mathrm{~g}$ ve $455.87 \mathrm{~kg} \mathrm{da}^{-1}$ olmaktadır. Elde edilen sonuçlardan görüldüğü gibi, istatistiksel göstergeler geçerli sinırlar (Willmott ve Matsuura, 2005) dahilinde değişmektedir.

Çizelge 1. Soyanın bazı agronomik parametrelerine ilişkin bazı tanımlayıcı istatistikler $(\mathrm{n}=40)$

\begin{tabular}{lcccccc}
\hline Özellikler & En düşük & En yüksek & Ortalama & Standart sapma & $V K, \%$ & Çarpıklık \\
\hline BB, cm & 88.33 & 127.27 & 103.31 & 9.91 & 9.59 & 1.127 \\
BTA, g & 164.10 & 242.91 & 200.54 & 17.81 & 8.88 & 0.505 \\
TV $_{\text { kg da }}{ }^{-1}$ & 280.32 & 593.16 & 455.87 & 81.71 & 17.92 & -0.410 \\
\hline
\end{tabular}

BB: Bitki boyu, BTA: Bin tane ağırlı̆̆, TV: Tane verimi, $V K$ : Varyasyon katsayısı

Soyada bitki boyu; çeşit, ekim sıklığı, ekim zamanı ve yetiştirme şartlarına bağlı olarak, 30-150 cm arasında değişim göstermektedir (Arıŏlu, 2000). Homer ve ark. (2000), Karadeniz Bölgesinin sahil ve geçit bölgelerine uygun soya çeşitlerini belirlemek ve geliştirmek amacıyla yapmış oldukları bir çalışmada, bitki boylarının $72.9 \mathrm{~cm}$ ile $128.8 \mathrm{~cm}$ arasında, bin tane ağırlığın $157.0 \mathrm{~g}$ ile $298.0 \mathrm{~g}$ arasında değiştiğini bildirmişlerdir. Soya verimini esas olarak tane ağırlığı ve tane sayısı belirlemekte ve tane sayısı birim alandaki bakla sayısına ve bakladaki tane sayısına bağlı olmaktadır (Karagül ve ark., 2011). Ay (2012) tarafından, Türkiye'de ıslah edilmiş yeni soya (Glycine max. l. merrill) çeşitlerinin Orta Karadeniz Bölgesi koşullarında verim ve kalite performanslarının belirlendiği bir çalışmada, Terme'de en yüksek tane veriminin $570.68 \mathrm{~kg} \mathrm{da}^{-1}$ ile Erensoy çeşidinde; en düşük tane verimin ise $335.50 \mathrm{~kg} \mathrm{da}^{-1}$ ile Üstün 1 çeşidinden elde edildiği bildirilmiştir.

\section{Soya tarımı yapılan toprakların fiziksel özelliklerinin değişimi}

Ovada soya fasülyesi yetiştirilen toprakların bazı fiziksel özelliklerine ait tanımlayıcı istatistikler Çizelge 2'de verilmiştir. 
Çizelge 2. Soya bitkisi yetiştirilen toprakların bazı fiziksel özelliklerine ait bazı tanımlayıcı istatistikler

\begin{tabular}{lcccccc}
\hline Özellikler & En düşük & En yüksek & Ortalama & St. Sapma & $V K, \%$ & Çarpıklık \\
\hline Kil, \% & 15.34 & 57.23 & 37.67 & 12.74 & 33.82 & -0.218 \\
Silt, \% & 12.19 & 54.02 & 37.04 & 11.14 & 30.07 & -0.752 \\
Kum, \% & 11.67 & 42.15 & 25.27 & 9.19 & 36.36 & 0.429 \\
Db, g cm ${ }^{-3}$ & 0.96 & 1.50 & 1.21 & 0.15 & 12.39 & 0.143 \\
TK, \% & 25.59 & 49.19 & 37.54 & 6.18 & 16.46 & 0.045 \\
SN, \% & 12.78 & 32.11 & 20.82 & 4.97 & 23.87 & 0.664 \\
BYS, \% & 12.55 & 23.01 & 16.71 & 2.56 & 15.32 & 0.203 \\
\hline
\end{tabular}

Db: Hacim ağırlı̆̆ı; TK: Tarla kapasitesi; SN: Solma noktası; BYS: Bitkiye yarayışlı su; VK: Varyasyon katsayısı.

Çizelge 2'den görüldüğü gibi; soya yetiştirilen toprakların kil miktarı \%15.34-57.23 arasında değişmekte, ortalama değeri ise \%37.67'dir. Standart sapması 12.74; varyasyon katsayısı \%33.82; çarpıklık ise -0.218 olarak saptanmıştır. Toprakların silt miktarı \%12.19-54.02 arasında değişmekte, ortalama silt miktarı \%37.04'tür. İstatistiksel parametreler sırasıyla 11.14; \%30.07; -0.752 olarak bulunmuştur. Toprakların kum miktarı \%11.67-42.15 arasında değișmekte olup, ortalama kum miktarı \%25.27 olarak belirlenmiștir. Standart sapma 9.19; varyasyon katsayısı \%36.36; çarpıklık 0.429 alarak saptanmıştır. Soya yetiştirilen toprakların bünyesi killi tın, kil, tın, siltli kil, siltli tın, siltli killi tın ve kumlu kil olarak belirlenmiştir. Toprakların minumum hacim ağırlı̆̆ $0.96 \mathrm{~g} \mathrm{~cm}^{-3}$, maksimum hacim ağırlığı ise $1.50 \mathrm{~g} \mathrm{~cm}^{-3}$ olup, ortalama değer $1.21 \mathrm{~g} \mathrm{~cm}^{-3}$ olarak bulunmuştur. Standart sapma, varyasyon katsayısı, çarpıklık katsayısı sırasıyla 0.15; \%12.39; 0.143 olarak belirlenmiştir. Toprakların TK \%25.59-49.19 arasında değişmekte olup, ortalama değeri \%37.54'tür. İstatistiksel göstergeler sırasıyla 6.18; \%16.46; 0.045 olarak saptanmıştır. Soya bitki topraklarının SN \%12.78-32.11 arasında değişmekte olup, ortalama değeri \%20.82'dir. Standart sapması 4.97; varyasyon katsayısı \%23.87; çarpıklık katsayısı ise 0.664 olarak belirlenmiştir. Soya bitki topraklarının BYS miktarı \%12.55-23.01 arasında değişmekte, ortalama miktarı \%16.71'dir. Standart sapma, varyasyon katsayısı, çarpıklık ölçütü sırasıyla 2.56; \%15.32; 0.203 olarak bulunmuştur.

Toprakların fiziksel özelliklerine ait tanımlayıcı istatistiklerden anlaşılan, elde edilen değerler geçerlilik sınırları dahilinde olmaktadır. Toprakların hacim ağırlığı, kil ve tarla kapasitesi değerlerine ait frekans dağılımları Şekil 2-4'de verilmiştir.

Soya yetiştirilen toprakların hacim ağırlığı değerlerinin $\% 7.5^{\prime} \mathrm{i}<1 \mathrm{~g} \mathrm{~cm}^{-3}, \%$ 62.5'i 1.0-1.3 $\mathrm{g} \mathrm{cm}^{-3}$ ve \%30'u 1.3-1.6 g cm${ }^{-3}$ olarak belirlenmiștir (Şekil 2). Elde edilen veriler hacim ağırlığının soya bitkisinin gelişiminde sınırlayıcı faktör olmadığını göstermektedir. Farklı toprak işleme uygulamalarının ve mısır kalıntılarının, 11 yıllık bir periyot boyunca toprağın hacim ağırlığına, soya bitkisinin gelişim sürecine ve verimine etkisinin araştırıldığı bir çalışmada, hacim ağırlık değerlerinin genellikle 0-10 cm derinlikte değişime uğradığı ve bu değişimin $0.9 \mathrm{~g} \mathrm{~cm}^{-3}$ ve $1.46 \mathrm{~g} \mathrm{~cm}^{-3}$ arasında olduğu belirlenmiştir (Dam ve ark., 2005). Hacim ağırlığ dinamik bir özelliktir. Hacim ağırlı̆̆ı; toprağın yapısı, bitki örtüsü ve mekanik uygulamalar, iklim koşulları, çeşitli tarım makinalarının kullanımı vb. faktörlere bağlı olarak değişmektedir (Arshad ve ark., 1996; Hu ve ark., 2012).

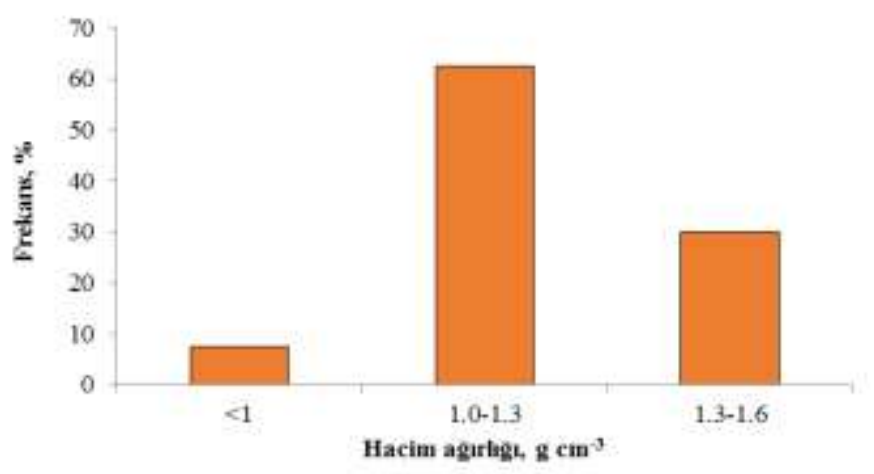

Şekil 2. Soya bitkisi yetiştirilen topraklarda hacim ağırlığı dağılımı $(n=40)$

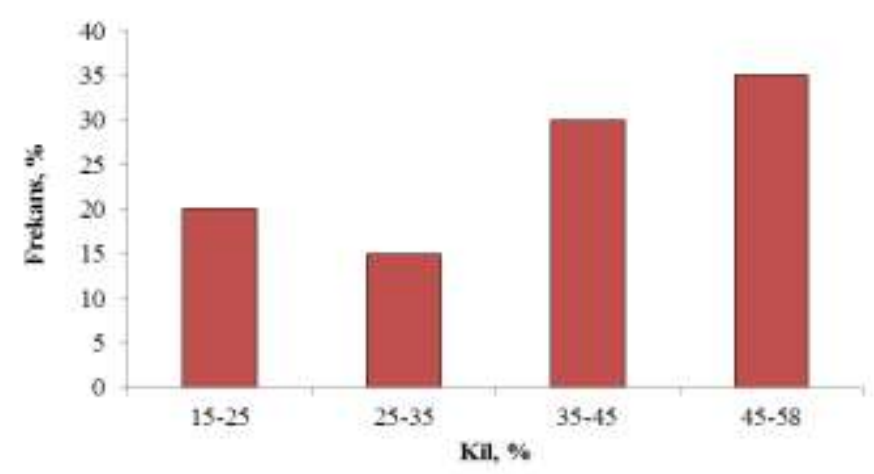

Şekil 3. Soya bitkisi yetiştirilen topraklarda kil miktarının dağılımı $(n=40)$ 
Soya bitkisi yetiştirilen topraklar genellikle kil ve killi tın bünyeye sahiptir. Soya bitkisi yetiştirilen araştırma topraklarında, en düşük kil miktarı \%15 ile \%25 arasında olup araștırma topraklarının \%20'sini; en yüksek kil miktarı ise \%45 ile \%57 arasında değişmekte, araștırma topraklarının \%35'ni oluşturmaktadır (Șekil 3). Soya bitkisi aşırı kumlu topraklar dışında kalan değişik toprak tiplerinde sorunsuz olarak yetiştirilebilmektedir. Üzerinde uzun süre suyun durgun kaldığı sıkışık ve havalanmayan topraklarda ise gelişmesi olumsuz etkilenmektedir (Ay, 2012). İşler ve Coşkan (2009), farklı bakteri (Bradyrhizobium japonicum) aşılama yöntemlerinin soyada azot fiksasyonu ve tane verimine etkisini araştırdıkları bir çalışmada, araştırma toprağının \%41 düzeyinde kil içerdiğini ve siltli kil bünyeye sahip olduğunu bildirmişlerdir.

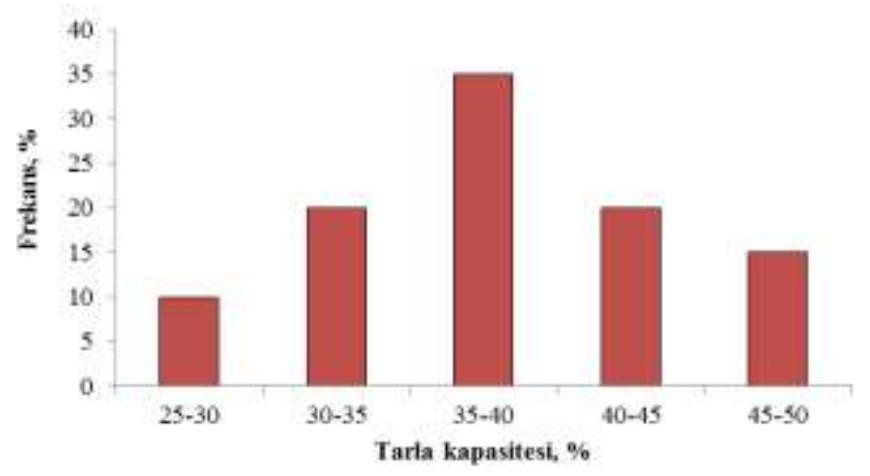

Şekil 4. Soya bitkisi yetiştirilen topraklarda tarla kapasitesi dağılımı $(n=40)$

Şekil 4'ten görüldüğü gibi, soya yetiştirilen toprakların \%10'unda tarla kapasitesi \%25 ile \%30; \%55'inde $\% 30$ ile \%40; \%35'inde ise \%40 ile \%50 arasında değișmektedir. Soyanın mevsimlik su ihtiyacı; yörenin iklimine, toprak ve çeşit özelliklerine bağlı olarak çok farklılıklar göstermekle beraber, 450-700 mm arasında değişmektedir (Korukçu ve Evsahipoğlu, 1981). Akgül ve Başayiğit (2005) tarafından, Süleyman Demirel Üniversitesi çiftlik topraklarının bazı fiziksel ve kimyasal özelliklerinin belirlendiği, toprakların sınıflandırıldığı, detaylı toprak haritası ve raporunun hazırlandığı bir çalışmada; alınan toprak örneklerinde tarla kapasitesinin \%16.41 ile \%33.9 arasında değiştiği bildirilmiştir.

\section{Soya tarımı yapılan toprakların kimyasal özelliklerinin değişimi}

Ovada soya fasülyesi yetiştirilen toprakların bazı kimyasal özelliklerine ait tanımlayıcı istatistikler Çizelge 3'de verilmiştir.

Çizelge 3. Soya bitki yetiștirilen toprakların bazı kimyasal özelliklerine ait bazı tanımlayıcı istatistikler $(n=40)$

\begin{tabular}{lcccccc}
\hline Özellikler & En düşük & En büyük & Ortalama & St. Sapma & $V K, \%$ & Çarpıklık \\
\hline $\mathrm{pH},(1: 1)$ & 7.00 & 8.02 & 7.72 & 0.21 & 2.72 & -1.566 \\
$\mathrm{EC}^{\mathrm{dS} \mathrm{m}} \mathrm{d}^{-1}(1: 1)$ & 0.40 & 0.98 & 0.60 & 0.14 & 23.33 & 0.881 \\
$\mathrm{CaCO}_{3}, \%$ & 0.55 & 13.45 & 5.84 & 4.08 & 69.86 & 0.154 \\
$\mathrm{OM} \%$ & 1.61 & 5.05 & 2.89 & 1.03 & 35.64 & 0.724 \\
$\mathrm{~N}, \%$ & 0.11 & 0.30 & 0.15 & 0.04 & 26.66 & 1.571 \\
$\mathrm{P}, \mathrm{ppm}$ & 1.74 & 38.26 & 13.68 & 10.08 & 73.68 & 0.890 \\
$\mathrm{~K}, \mathrm{cmol} \mathrm{kg}{ }^{-1}$ & 0.17 & 1.17 & 0.56 & 0.20 & 35.71 & 0.783 \\
$\mathrm{Ca}+\mathrm{Mg}_{\mathrm{cmol} \mathrm{kg}}{ }^{-1}$ & 29.03 & 94.39 & 50.52 & 17.02 & 308.33 & 0.692 \\
$\mathrm{Na}, \mathrm{cmol} \mathrm{kg}{ }^{-1}$ & 0.35 & 2.46 & 1.37 & 0.70 & 51.09 & -0.346 \\
$\mathrm{KDK}, \mathrm{cmol} \mathrm{kg}^{-1}$ & 30.05 & 96.96 & 52.47 & 17.30 & 32.97 & 0.693 \\
$\mathrm{Fe}, \mathrm{ppm}$ & 21.99 & 60.74 & 33.85 & 9.65 & 28.50 & 0.858 \\
$\mathrm{Mn}, \mathrm{ppm}$ & 4.95 & 31.49 & 11.68 & 5.27 & 45.11 & 2.679 \\
$\mathrm{Cu}, \mathrm{ppm}$ & 2.27 & 9.37 & 5.81 & 1.61 & 27.71 & 0.031 \\
$\mathrm{Zn}, \mathrm{ppm}$ & 0.29 & 1.26 & 0.58 & 0.19 & 32.75 & 1.503 \\
\hline
\end{tabular}

pH: Toprak reaksiyonu; EC: Elektriksel iletkenlik; $\mathrm{CaCO}_{3}$ : Kireç; OM: Organik madde; N: Azot; P: Fosfor; K: Potasyum; Ca+Mg: Kalsiyum+Magnezyum; Na: Sodyum; KDK: Katyon değişim kapasitesi; Fe: Demir; Mn: Mangan; Cu: Bakır; Zn: Çinko; VK: Varyasyon katsayısı. 
Çizelge 3' den görüldüğü gibi, soya yetiştirilen topraklar genellikle nötr ile hafif alkalin reaksiyona sahip olup, ortalama pH değeri 7.72 'dir. Standart sapma, varyasyon katsayısı, çarpıklık ölçütü sırasıyla 0.21 ; \%2.72; -1.566 olarak belirlenmiştir. Topraklar çoğunlukla tuzsuz olup, ortalama EC miktarı 0.60'dır. Standart sapma 0.14; varyasyon katsayısı \%23.33; çarpıklık katsayısı ise 0.881 olarak belirlenmiştir. Soya bitkisi toprakları, kireç içeriği bakımından kireçsiz ile orta kireçli düzey arasında değişmekte olup, ortalama kireç miktarı \%5.84 olarak bulunmuştur. İstatistiksel göstergeler sırasıyla 4.08; \%69.86; 0.154 olarak saptanmıştır. Toprakların organik madde kapsamı çoğunlukla orta seviyede olup, ortalama miktarı \%2.89'dur. Standart sapma, varyasyon katsayısı, çarpıklık sırasıyla 1.03; \%35.64; 0.724 olarak belirlenmiştir. Toprakların azot miktarı genellikle orta düzeyde olup, ortalama azot miktarı \%0.15'tir. Standart sapma 0.04; varyasyon katsayısı \%26.66; çarpıklık katsayısı ise 1.571 olarak bulunmuştur. Toprakların fosfor miktarı en düşük 1.74 ppm, en yüksek 38.26 ppm'dir. Ortalama fosfor miktarı 13.68 ppm olup, toprakların fosfor kapsamı çoğunlukla az ve iyi düzeydedir. İstatistiksel göstergeler sırasıyla 10.08; \%73.68; 0.890 olarak belirlenmiştir. Toprakların potasyum kapsamı çoğunlukla orta seviyede olup, ortalama potasyum miktarı $0.56 \mathrm{cmol} \mathrm{kg}-1$ 'dır. Standart sapma 0.20; varyasyon katsayısı \%35.71; çarpıklık katsayısı se 0.783 olarak bulunmuştur. Topraklarda Ca+Mg miktarı 29.03-94.39 $\mathrm{cmol} \mathrm{kg}^{-1}$ arasında değişmekte olup, ortalama miktarı $50.52 \mathrm{cmol} \mathrm{kg-1'dır.} \mathrm{İstatistiksel} \mathrm{parametreler} \mathrm{ise} \mathrm{sırasıyla} \mathrm{17.02;} \mathrm{\% 308.33;} 0.692$ olarak saptanmıştır. Topraklar sodyum bakımından orta ile yüksek arasında değișmekte ve ortalama sodyum miktarı $1.37 \mathrm{cmol} \mathrm{kg-1'dır.} \mathrm{Standart} \mathrm{sapma} \mathrm{0.70;} \mathrm{varyasyon} \mathrm{katsayısı} \mathrm{\% 51.09;} \mathrm{çarpıklık} \mathrm{katsayısı} \mathrm{ise}-0.346$ olarak bulunmuştur. Topraklardaki KDK miktarı genellikle yüksek ve çok yüksek düzeyde değişmekte olup, ortalama KDK miktarı $52.47 \mathrm{cmol} \mathrm{kg-1'dır.} \mathrm{Standart} \mathrm{sapma,} \mathrm{varyasyon} \mathrm{katsayısı,} \mathrm{çarpıklık} \mathrm{ölçütü} \mathrm{sırasıyla}$ 17.30; \%32.97; 0.693 olarak belirlenmiştir. Soya bitkisi topraklarının demir kapsamı çoğunlukla orta ile yüksek arasında değişmekte, ortalama demir miktarı 33.85 ppm'dir. İstatistiksel parametreler sırasıyla 9.65; \%28.50; 0.858 olarak bulunmuştur. Toprakların mangan kapsamı genellikle düşük düzeyde olup, ortalama mangan miktarı 11.68 ppm olmaktadır. Standart sapma 5.27; varyasyon katsayısı \%45.11; çarpıklık katsayısı ise 2.679 olarak belirlenmiştir. Toprakların bakır kapsamı çok yüksek olup, ortalama bakır miktarı 5.81 ppm'dir. İstatistiksel göstericiler sırasıyla 1.61; \%27.71; 0.031 olarak saptanmıştır. Toprakların çinko kapsamı çoğunlukla çok düşük düzeyde ve ortalama çinko miktarı $0.58 \mathrm{ppm}$ olarak bulunmuştur. Standart sapma, varyasyon katsayısı, çarpıklık sırasıyla 0.19; \%32.75; 1.503 olarak belirlenmiştir. Kültivasyon işlemleri ve organik madde, kireç, gübreler ve sentetik toprak düzenleyicilerin toprağa ilavesi gibi insanlar tarafından oluşturulan uygulamalar bazı toprak özelliklerinin $\left(\mathrm{P}, \mathrm{CaCO}_{3}, \mathrm{Ca}+\mathrm{Mg}\right.$ ) geniș aralıkta değișimine, dolayısıyla değerlerin heterojen dağılımına ve varyasyon katsayılarının yüksek olmasına sebep olabilir.

Soya bitkisi yetiştirilen toprakların $\mathrm{pH}$, elektriksel iletkenlik, organik madde, azot, fosfor, potasyum ve katyon değişim kapasitesi miktarına ait frekans dağılımları Şekil 5-11'de gösterilmiştir.

Şekil 5'ten görüldügü gibi, soya bitkisi yetiştirilen araştırma topraklarının \%7.5'i nötr ve çok hafif alkalin, $\% 92.5$ 'i ise hafif alkalin reaksiyonludur. Toprak reaksiyonu soya için oldukça önemlidir ve genellikle pH'nın 6.0-7.5 arasında olması istenmektedir (Ay, 2012). Yetkin ve Arıoğlu (2009) tarafından, Çukurova Bölgesi'nde ana ürün koşullarında bazı soya çeşitlerinin verim ve tarımsal özelliklerinin belirlenmesine ait bir çalışmada; toprak pH'sının 7.28 ile 7.29 arasında değiștiği, toprakların genellikle nötr bir reaksiyona sahip olduğu bildirilmiştir.

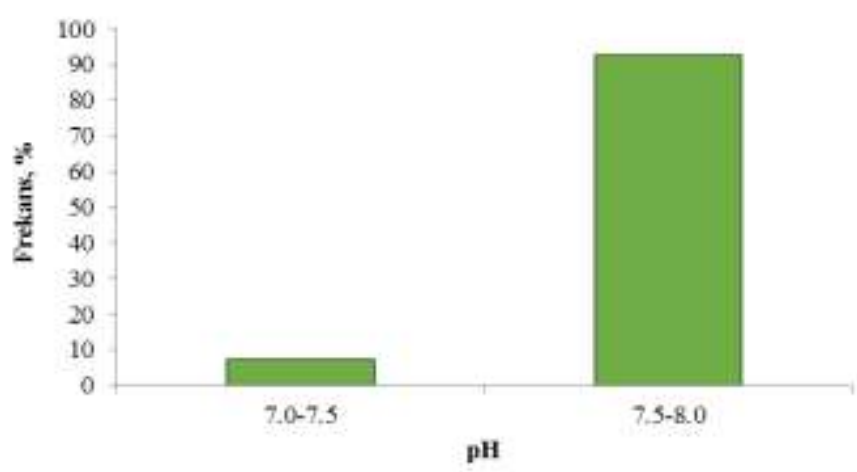

Şekil 5. Soya bitkisi yetiştirilen topraklarda $\mathrm{pH}$ değerlerinin dağılımı $(n=40)$

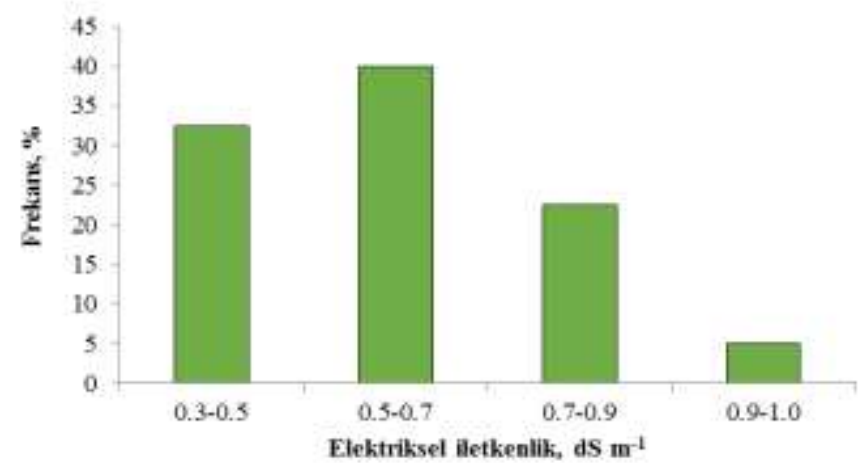

Şekil 6. Soya bitkisi yetiştirilen topraklarda elektriksel iletkenlik değerlerinin dağılımı $(n=40)$ 
Soya bitkisi yetiştirilen araştırma topraklarının elektriksel iletkenlik değerlerinin \%32.5'si 0.3-0.5 dS m-1; \%40'1 0.5-0.7 dS m-1; \%22.5'i 0.7-0.9 dS m-1; \%5'i ise 0.9-1.0 dS m-1 arasında olup, toprakların tuzluluk probleminin bulunmadığı ifade edilebilir (Şekil 6). Genel olarak, tuzlu ve çorak topraklarda soya bitkisinin verimi azalmaktadır (İşler, 1992).

Organik madde miktarı, soya fasülyesi yetiştirilen toprakların \%20'inde az (\%1-2), \%47.5'inde orta (\%2-3), $\% 15$ 'inde iyi (\%3-4) ve \%17.5'inde yüksek (>\%4) olarak belirlenmiştir (Şekil 7). Adiloğlu ve Adiloğlu (2004), Trabzon yöresinde yapmıș olduğu bir araştırmada; alınan 30 adet toprak örneğinde organik madde miktarlarının \%1.62-7.16 arasında değiștiğini, örneklerin \%56.7'sinin yüksek seviyede organik madde içerdiğini bildirmişlerdir.

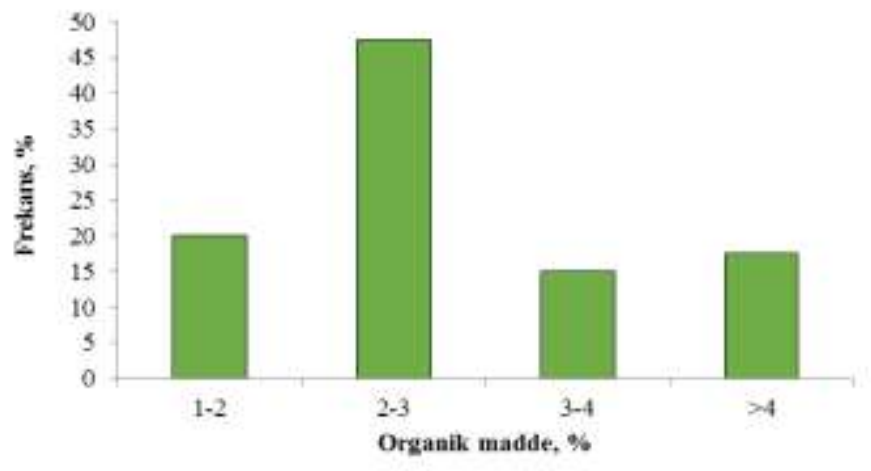

Şekil 7. Soya bitkisi yetiştirilen topraklarda organik madde miktarının dağılımı $(\mathrm{n}=40)$

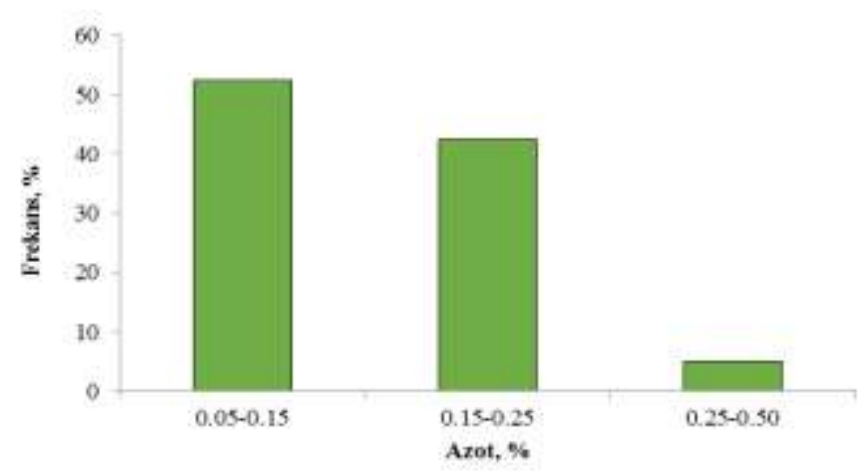

Şekil 8. Soya bitkisi yetiştirilen topraklarda azot miktarının dağılımı $(\mathrm{n}=40)$

Soya bitkisi yetiştirilen araştırma topraklarının \%52.5'inde azot miktarı düşük (\%0.05-0.15), \%42.5'inde orta (\%0.15-0.25), \%2'sinde ise fazla (\%0.25-0.50) seviyede tespit edilmiștir (Şekil 8). Soya fasulyesi, uygun koşullar altında ihtiyaç duyduğu azotun \% 40-60'ını fiksasyon yoluyla karşılamakta (Ham ve Caldwell, 1978) ve soya tarla bitkileri arasında azota en çok gereksinim duyan bitkidir (Sindir ve Dewit, 1975). Soya $100 \mathrm{~kg}$ tane üretimi için yaklaşık olarak $10 \mathrm{~kg}$ azot kullanmaktadır (Hardy ve ark., 1980).

Soya bitkisi yetiştirilen araştırma alanında az (<6 ppm), orta (6-14 ppm), iyi (14-26 ppm), yüksek (26-38 ppm) ve çok yüksek (>38 ppm) fosfor miktarları, araştırma alanının sırasıyla \%32.5; \%25; \%27.5; \%10 ve \%5 kısmını oluşturmaktadır (Şekil 9). Özyazıcı ve ark. (2016) tarafından, Orta ve Doğu Karadeniz Bölgesi tarım topraklarının temel verimlilik düzeylerinin belirlendiği bir çalışmada, araştırma topraklarının $\mathrm{P}$ içerikleri incelendiğinde, Rize ili tarım toprakları hariç diğer illerde ve bölge genelinde oransal olarak yarıdan fazlasında (bölge geneli olarak \%58.83'ünde) fosforun çok az ve az; Giresun ili sinırları içerisinden alınan toprak örneklerinin \%67.39'unun çok az ve az; Rize ili tarım alanlarında ise toprak örneklerinin \%59.75'inin yüksek ve çok yüksek düzeyde olduğu bildirilmiştir.

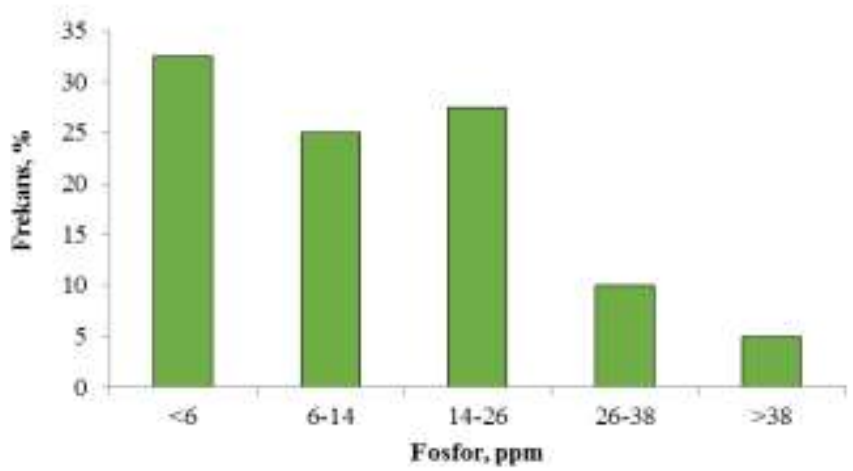

Şekil 9. Soya bitkisi yetiştirilen topraklarda fosfor miktarının dağılımı $(\mathrm{n}=40)$

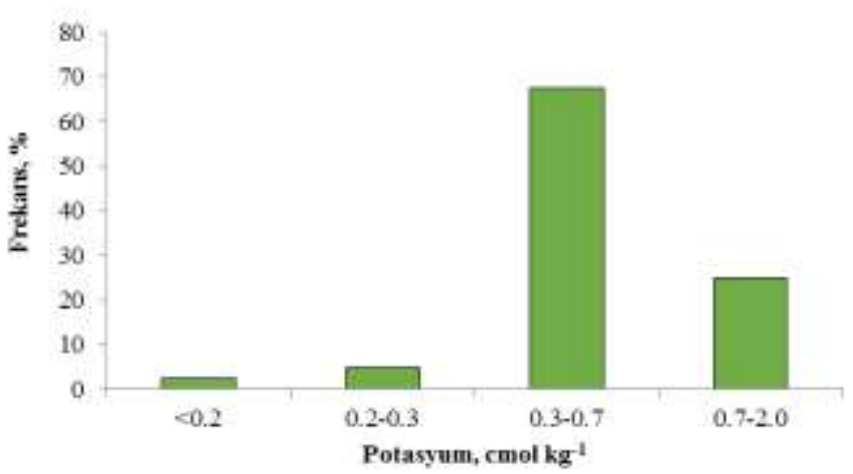

Şekil 10. Soya bitkisi yetiştirilen topraklarda potasyum miktarı dağılımı $(\mathrm{n}=40)$

Şekil 10'dan görüldüğü gibi; soya fasülyesi yetiştirilen araştırma topraklarının $\% 2.5$ 'inde potasyum miktarı çok düşük $\left(<0.2 \mathrm{cmol} \mathrm{kg}^{-1}\right), \% 5^{\prime}$ inde düşük $\left(0.2-0.3 \mathrm{cmol} \mathrm{kg}^{-1}\right)$, \%67.5'inde orta $\left(0.3-0.7 \mathrm{cmol} \mathrm{kg}^{-1}\right)$, \%25'inde 
ise yüksek (0.7-2.0 $\mathrm{cmol} \mathrm{kg}^{-1}$ ) olarak saptanmıştır. Genel olarak araştırma topraklarında potasyum kapsamı orta düzeydedir. Bursa yöresi rendzina büyük toprak grubu topraklarının bazı özellikleri ve besin maddesi içeriklerinin belirlendiği bir çalışmada, toprakların değișebilir potasyum içeriklerinin $0.30 \mathrm{cmol} \mathrm{kg}^{-1} \mathrm{ile} 1.20$ cmol kg-1 arasında olduğu, toprakların \%80.8'inin iyi, yüksek ve çok yüksek düzeylerde değişebilir potasyum kapsadığı saptanmıştır (Tümsavaş ve Aksoy, 2008).

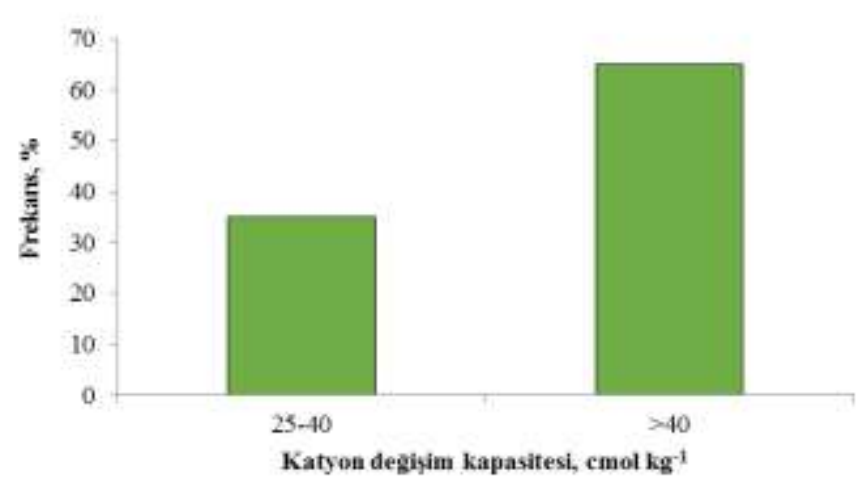

Şekil 11. Soya bitkisi yetiştirilen topraklarda katyon değişim kapasitesi değerleri dağılımı (n=40)

Soya fasülyesi yetiştirilen çalışma alanı topraklarında ortalama KDK değeri $52.47 \mathrm{cmol} \mathrm{kg}^{-1}$ 'dır (Çizelge 3). Yüksek (25-40 $\mathrm{cmol} \mathrm{kg}^{-1}$ ), çok yüksek (>40 $\left.\mathrm{cmol} \mathrm{kg}^{-1}\right)$ düzeyde KDK miktarları, alanın sırasıyla \%35 ve \%65'ini oluşturmaktadır (Şekil 11). Genel olarak, araştırma topraklarında KDK miktarı çok yüksektir. Taban ve ark. (2004), Taşköprü Yöresinde sarımsak tarımı yapılan toprakların verimlilik durumu ve potansiyel beslenme problemlerini belirledikleri bir araştırmada; toprakların katyon değişim kapasitesinin 15.61-31.51 cmol kg-1 arasında değiştiğini, toprakların \%85'inde katyon değişim kapasitesinin $25 \mathrm{cmol} \mathrm{kg}^{-1}$ 'dan büyük, $\% 15$ 'inde ise $15-25 \mathrm{cmol} \mathrm{kg}^{-1}$ arasında olduğunu bildirmişlerdir.

\section{Sonuc}

Çarşamba Ovası'nda çiftçiler tarafından soya bitkisi yetiştirilen tarım topraklarının bazı fiziksel ve kimyasal özellikleri belirlenerek, toprakların verimlilik durumları incelenmiştir. Araştırma sonuçlarına göre; soya bitkisi yetiştirilen tarım arazileri çoğunluğu killi ve killi tınlı bünyeye sahiptir. Toprakların hacim ağırlı̆ı değerleri 0.96-1.50 $\mathrm{gr} \mathrm{cm}^{-3}$ aralığında değişmektedir. Soya yetiştirilen toprakların \%55'inde tarla kapasitesi \%30 ile \%40 arasında belirlenmiștir. Toprakların solma noktası ve bitkiye yarayıșlı su miktarının ortalama değerleri sırasıyla \%20.82; \%16.71 olarak saptanmıștır. Dolayısıyla, toprakların bünyesi, hacim ağırlığı, tarla kapasitesi gibi fiziksel özellikleri, genel olarak araștırma topraklarından yüksek soya verim elde edilmesini sınırlandıran faktörler olarak görülmemektedir. Toprakların \%92.5'inin hafif alkali reaksiyonlu, tuzluluk probleminin olmadığı, büyük bir kısmının az kireçli olduğu; organik madde miktarının \%67.5'inin az ve orta, \%32.5'inin ise iyi ve yüksek düzeyde olduğu belirlenmiștir. Azot miktarı araștırma topraklarının \%52.5'inde düşük, \%42.5'inde ise orta seviyededir. Toprakların organik madde ve azot içeriklerinin genel olarak düşük olmasından dolayı, topraklara organik ve azotlu gübrelerin verilmesi faydalı olacaktır. Toprakların büyük kısmı fosfor bakımından zengin olmadığından fosforlu gübrelemeye ihtiyaç duyulmaktadır. Araștırma topraklarının \%67.5'inde potasyum kapsamı orta, \%25'inde yüksek; katyon değişim kapasitesi ise \%35'inde yüksek, \%65'inde çok yüksek olmaktadır. Topraklarının \%65'inde demir yüksek, \%92.5'inde bakır çok yüksek, \%85'inde mangan düşük, \%90'ında ise çinko çok düşük düzeyde saptanmıştır. Ayrıca araştırma topraklarının çoğunluğunda görülen mangan noksanlığı, ovada tarımsal üretimi sınırlayıcı bir faktör olarak ortaya çıkabilir. Toprakların büyük çoğunluğunun (\% 90’1) düşük düzeyde çinko içermesi soya bitkisinde çinko noksanlığı belirtilerinin ortaya çıkması olasılığını yükseltmekte, dolayısıyla çinko gübrelemesinin yapılması gereklidir. Bu araştırma sonuçları ova topraklarında yetiştirilen soya bitkisinin besin elementi durumunu tam olarak ortaya koyamayacağından, bitkilerin en yüksek verim düzeyine uygun besin elementi isteklerinin detaylı olarak araştırılması, hem toprakta hem de bitkide besin elementleri içeriklerinin belirlenmesi ve besin elementleri noksanlığının giderilmesi için uygun tarımsal işlemlerin ve gübreleme programlarının yapılması gerekmektedir.

\section{Kaynaklar}

Adams TC, Brye KR, Purcell LC, Ross J, Gbur EE, Savin MC, 2017. Soil property predictors of soybean yield using yield contest sites. Journal of Crop Improvement, 31(6): 816-829. 
Adiloğlu A, Adiloğlu S, 2004. An investigation on nutritional problems of hazelnut (Corylus avellana) grown in acid soils of Turkey. Pakistan Journal of Biological Sciences, 7(8): 1433-1437.

Akgül M, Başayiğit L, 2005. Süleyman Demirel Üniversitesi çiftlik arazisinin detaylı toprak etüdü ve haritalanması. Süleyman Demirel University Journal of Natural and Applied Sciences, 9: 54-63.

Anonim, 1984. Samsun İli Arazi Varlığı. T.C. Tarım Orman ve Köy İşleri Bakanlığı, Toprak Su Genel Müdürlüğü Yayınları, Ankara. İl rapor No: 55; Genel yayın No: 748.

Anonim, 2013. Tohumluk Tescil ve Sertifikasyon Merkez Müdürlüğü. (https://www.tarimorman.gov.tr/BUGEM/TTSM/Belgeler/Tescil/Teknik\%20Talimatlar/End\%C3\%BCstri\%20 Bitkileri/soya.pdf) (Erişim tarihi: 25.01.2019).

Anonim, 2016. Türkiye İstatistik Kurumu Temel İstatistikler. http://www.tuik.gov.tr (Erişim Tarihi: 17.04.2017).

Arıoğlu H, 2000. Yağ Bitkileri Yetiştirme Ve Islahı. Ders Kitapları Yayın No:A-70C. Çukurova Üniversitesi Ziraat Fakültesi, Adana, Genel yayın No:220.

Arshad MA, Lowery B, Grossman B, 1996. Physical Tests for Monitoring Soil Quality. In: Doran JW, Jones AJ (Editors). Methods for Assessing Soil Quality, Soil Science Society of America Special Publication. Soil Science Society of America, Madison Wisconsin USA, 49: 123-142.

Ay B, 2012. Türkiye'de sslah edilmiş yeni soya (Glycine Max. L. Merrill) çeşitlerinin Orta Karadeniz Bölgesi koşullarında verim ve kalite performanslarının belirlenmesi. Yüksek Lisans Tezi, Ondokuz Mayıs Üniversitesi Fen Bilimleri Enstitüsü Tarla Bitkileri Anabilim Dalı, Samsun.51s.

Aulakh MS, Pasricha NS, Bahl GS, 2003. Phosphorus fertilizer response in an irrigated soybean-wheat production system on a subtropical, semiarid soil. Field Crops Research, 80: 99-109.

Başar H, 2001. Bursa ili topraklarının verimlilik durumlarının toprak analizleri ile incelenmesi. Uludağ Üniversitesi Ziraat Fakültesi Dergisi, 15(2): 69-83.

Bayraklı F, 1987. Toprak ve Bitki Analizleri. Ondokuz Mayıs Üniversitesi Yayınları, No:17, Samsun.

Black CA, 1965. Methods of Soil Analysis Part I-Physical and Mineralogical Methods. Soil Science Society of America, USA, No: 9.

Brye KR, Cordell ML, Longer DE, Gbur EE, 2007. Residue management practice effects on soil surface properties in a young wheat-soybean double-crop system. Journal of Sustainable Agriculture, 29(2): 121-150.

Coşkan A, İşler E, Küçükyumuk Z, Erdal İ, 2009. Isparta koşullarında soyada bakteri aşılamasının nodülasyona ve dane verimine etkisi. Süleyman Demirel Üniversitesi Ziraat Fakültesi Dergisi, 4 (2): 17-27.

Dam RF, Mehdi BB, Burgess MSE, Madramootoo CA, Mehuys GR, Callum IR, 2005. Soil bulk density and crop yield under eleven consecutive years of corn with different tillage and residue practices in a sandy loam soil in central Canada. Soil \& Tillage Research, 84: 41-53.

Demiralay İ, 1993. Toprak Fiziksel Analizleri. Atatürk Üniversitesi Ziraat Fakültesi Yayınları, Erzurum, No: 143.

Dengiz 0, Ekberli İ, 2017. Bazı vertisol alt grup topraklarının fizikokimyasal ve ısısal özelliklerinin incelenmesi. Akademik Ziraat Dergisi, 6(1): 45-52.

Ekberli İ, Kerimova E, 2005. Azerbaycan'ın Şirvan bölgesinde sulanan killi bir toprağın bazı fiziksel-kimyasal parametrelerinin değişimi. Ondokuz Mayıs Üniversitesi Ziraat Fakültesi Dergisi, 20(3): 54-59.

Fageria NK, Moreira A, Moraes LAC, Moraes MF, 2014. Influence of lime and gypsum on yield and yield components of soybean and changes in soil chemical properties. Communications in Soil Science and Plant Analysis, 45(3): 271283.

Gavili E, Moosavi AA, Zahedifar M, 2019. Integrated effects of cattle manure-derived biochar and soil moisture conditions on soil chemical characteristics and soybean yield. Archives of Agronomy and Soil Science, 65(12): 1758-1774.

Gülser C, Demir Z, İç S, 2010. Changes in some soil properties at different incubation periods after tobacco waste application. Journal of Environmental Biology, 31(5): 671-674.

Gülser C, 2016. Changes in soil physical properties with hazelnut husk and tobacco waste applications. VII International Scientific Agriculture Symposium," Agrosym 2016", 6-9 October, Jahorina, Bosnia and Herzegovina. Proceedings, pp. 2032-2036.

Gülser C, Ekberli İ, Candemir F, Demir Z, 2016. Spatial variability of soil physical properties in a cultivated field. Eurasian Journal of Soil Science, 5(3): 192-200.

Gürbüz MG, Kayalı E, Bahar E, Öz TA, Kurșun İ, 2019. Trakya topraklarının veri tabanının olușturulması ve bazı toprak özellikleri. Toprak Bilimi ve Bitki Besleme Dergisi, 7(1) 28-36.

Ham GE, Caldwell AC, 1978. Fertilizer placement effects on soybean seed yield n fixation and uptake. Agronomy Journal, 70: 779-783.

Hansen NC, Jolley VD, Naeve SL, Goos RJ, 2004. Iron deficiency of soybean in the North Central U.S. and associated soil Properties. Soil Science and Plant Nutrition, 50(7): 983-987.

Harasim E, Gawęda D, Wesołowski M, Kwiatkowski C, Goco M, 2016. Cover cropping influences physico-chemical soil properties under direct drilling soybean. Acta Agriculturae Scandinavica, Section B-Soil and Plant Science, 66(1): 85-97.

Hardy RWF, Havelka UD, Heytler PG, 1980. Nitrogen input with emphasis on $\mathrm{n}_{2}$ fixation in soybeans (Corbin FT, Editör). World Soybean Research Conference II: Proceedings, Westview Press, Corolado, USA, pp.57-72. 
Homer, A. D., Özçelik, H., Üstün, A., 2000. Karadeniz bölgesi soya ıslahı çalışmaları. Karadeniz Tarımsal Araştırma Enstitüsü Müdürlüğü. 1999 yılı teklif, gelişme ve sonuç raporları, Samsun, s. 22-30.

Hossain MF, Chen W, Zhang Yu, 2015. Bulk density of mineral and organic soils in the Canada's arctic and sub-arctic. Information Processing in Agriculture, 2: 183-190.

$\mathrm{Hu}$ W, Shao MA, Si BC, 2012. Seasonal changes in surface bulk density and saturated hydraulic conductivity of natural landscapes. European Journal Of Soil Science, 63: 820-830.

İşler N, 1992. GAP Bölgesinde soya yetiştiriciliğinde olabilecek sorunlar ve çözüm yolları. Güney Doğu Anadolu Bölgesinde İkinci Ürün Tarımı ve Sorunları Sempozyumu. 26-28 Ekim, 1992.

İşler E, Coşkan A, 2009. Farklı bakteri (bradyrhizobium japonicum) aşılama yöntemlerinin soyada azot fiksasyonu ve tane verimine etkisi. Ankara Üniversitesi Ziraat Fakültesi Tarım Bilimleri Dergisi, 15(4): 324-331.

Jackson ML, 1962. Soil Chemical Analysis. Prentice Hall. Inc. Englewood Cliffs, New Jersey, USA, pp. $219-221$.

Kacar B, 1994. Bitki ve Toprağın Kimyasal Analizleri III, Toprak Analizleri. Ankara Üniversitesi Ziraat Fakültesi, Eğitim Araştırma ve Geliștirme Vakfı Yayınları, No: 3, Ankara.

Karagül ET, Ay N, Meriç Ş, Huz E, 2011. Ege Bölgesi'nde ana ürün olarak yetiştirilen bazı soya genotiplerinin verimi, verim öğeleri ve nitelikleri üzerinde bir araștırma. Journal of Anadolu, 21(2): 59-66.

Kars N, Ekberli İ, 2019a. Çarşamba Ovası'nda işlenen tarım alanlarının bazı fiziksel ve kimyasal toprak özelliklerinin incelenmesi. Anadolu Tarım Bilimleri Dergisi, 34: 210-219.

Kars N, Ekberli İ, 2019b. Çarşamba Ovasının buğday bitkisi altındaki topraklarının bazı fiziksel ve kimyasal özelliklerinin incelenmesi. Toprak Su Dergisi, 8(1): 18-28.

Kırmızı S, Tüfekçi S, 1993. Bitlis Bölgesi tarım topraklarının potasyum durumu ve bunların bazı toprak özellikleri ile iliskileri. Yüzüncü Yıl Üniversitesi Ziraat Fakültesi Dergisi, 3(1-2): 187-203.

Kitou M, Yoshida S, 1994. Mulching effect of plant residues on soybean growth and soil chemical properties. Soil Science and Plant Nutrition, 40(2): 211-220.

Korukçu A, Evsahipoğlu AM, 1981. Soya ve sulanması. Tarım ve Mühendislik Dergisi. Türkiye Ziraat Odaları Birliği, Zirrat Mühendisliği Odası Yayınları, Ankara, 6: 23-26.

Lindsay L, Norvell WA, 1978. Development of a DTPA soil test for zinc, iron, manganese and copper. Soil Science Society of America Journal, 42(3): 421-428.

Lipiec J, Usowicz B, 2018. Spatial relationships among cereal yields and selected soil physical and chemical properties. Science of the Total Environment, 633: 1579-1590.

Moreira A, Moraes LA, Furlan T, Heinrichs R, 2016. Effect of glyphosate and zinc application on yield, soil fertility, yield components, and nutritional status of soybean. Communicatıons in Soil Science and Plant Analysis, 47(8): 10331047.

Moreira A, Moraes LAC, Moretti LG, 2017. Yield, yield components, soil chemical properties, plant physiology, and phosphorus use efficiency in soybean genotypes. Communications in Soll Science and Plant Analysis, 48(20): 2464-2476.

Moreira A, Moraes LAC, Aquino GS, 2018. Iron and manganese effect on soil chemical properties, yield components, and nutritional status of soybean. Communications in Soil Science and Plant Analysis, 49(15): 1844-1854.

Ngakou A, Megueni C, Makalao, MM, Nwaga D, Taine J, Ndjouenkeu R, 2008. Changes in the physico-chemical properties of soil and harvested soybean seeds in response to soil solarization and bradyrhizobial inoculation. Archives of Agronomy and Soil Science, 54(2): 189-202.

Olsen SR, Cole CV, Watanabe FS, Dean LA, 1954. Estimation of available phosphorus in soil by extraction with sodium bicarbonate. U.S. Department of Agriculture, Circular No: 939.

Öner T, 2006. Soya Sektör Raporu. İstanbul Ticaret Odası İstatistik Şubesi, İstanbul, 48 s. https://www.yumpu.com/tr/document/read/23584997/soya-sektor-raporu-ito (Erişim tarihi: 28.01.2020)

Özyazıcı MA, Aydoğan M, Bayraklı B, Dengiz 0, 2013. Doğu Karadeniz bölgesi kırmızı-sarı podzolik toprakların temel karakteristik özellikleri ve verimlilik durumu. Anadolu Journal of Agricultural Sciences, 28(1): 24-32.

Özyazıcı MA, Dengiz O, Aydoğan M, Bayraklı B, Kesim E, Urla Ö, Yıldız H, Ünal E, 2016. Orta ve Doğu Karadeniz bölgesi tarım topraklarının temel verimlilik düzeyleri ve alansal dağılımları. Anadolu Tarım Bilimleri Dergisi, 31(1): 136148.

Richards LA, 1954. Diagnosis and Improvement of Saline and Alkali Soils. United States Department of Agriculture, Handbook No: 60, pp. 105-106.

Sağlam MT, 1997. Toprak ve Suyun Kimyasal Analiz Yöntemleri. Tekirdağ Üniversitesi Ziraat Fakültesi Yayınları, No: 189.

Sancan M, Karaca S, 2017. Van- Erciş ilçesi Bayramlı köyü bağ alanlarının bazı toprak özelliklerinin belirlenmesi ve coğrafi bilgi sistemleri ile haritalanması. Toprak Bilimi ve Bitki Besleme Dergisi, 5 (2): 55-62.

Sato T, Kaneta Y, Furuta N, Kobayashi H, Shindo H, Ota T, Sato A, 2003. Effect of soil physical properties on soybean nodulation and $\mathrm{N}_{2}$ fixation at the early growth stage in heavy soil field in Hachirougata Polder, Japan. Soil Science and Plant Nutrition, 49(5): 695-702.

Sindir TR, Dewit D, 1975. Phostosynthate and n requirements for seed production by various. Crops Science, 189: 565567.

Taban S, Çıkılı Y, Kebeci F, Taban N, Sezer SM, 2004. Taşköprü yöresinde sarımsak tarımı yapılan toprakların verimlilik durumu ve potansiyel beslenme problemlerinin ortaya konulması. Tarım Bilimleri Dergisi, 10(3): 297-304. 
Temperly RJ, Borges R, 2006. Tillage and crop rotation impact on soybean grain yield and composition. Agronomy Journal, 98: 999-1004.

Turan M, Dengiz O, Demirağ İ, 2018. Samsun ilinin Newhall modeline göre Toprak sıcaklık ve nem rejimlerinin belirlenmesi. Türkiye Tarımsal Araștırmalar Dergisi, 5(2): 131-142.

Tümsavaş Z, Aksoy E, 2008. Bursa yöresi rendzina büyük toprak grubu topraklarının bazı özellikleri ve besin maddesi içerikleri. . Uludağ Üniversitesi Ziraat Fakültesi Dergisi, 2(1): 95-106.

Tümsavaş Z, Aksoy E, 2009. Kahverengi orman büyük toprak grubu topraklarının verimlilik durumlarının belirlenmesi. Uludağ Üniversitesi Ziraat Fakültesi Dergisi, 23(1): 93-104.

U.S. Salinity Laboratory Staff., 1954. Diagnosis and Improvement of Saline and Alkali Soils, Agriculture. Handbook No:60, United States Department of Agriculture, Washington DC, USA. 160p.

Verkler TL, Brye KR, Popp JH, Gbur EE, Chen P, Amuri N, 2009. Soil properties, soybean response, and economic return as affected by residue and water management practices. Journal of Sustainable Agriculture, 33(7): 716-744.

Virk HK, Singh G, Sharma P, 2017. Effect of tillage, crop residues of preceding wheat crop and nitrogen levels on biological and chemical properties of soil in the soybean-wheat cropping system. Communications in Soil Science and Plant Analysis, 48(15): 1764-1771,

Willmott CJ, Matsuura K, 2005. Advantages of the mean absolute error (MAE) over the root mean square error (RMSE) in assessing average model performance. Climate Research, 30(1): 79-82.

Yetkin SG, Arıoğulu H, 2009. Çukurova bölgesinde ana ürün koşullarında bazı soya çeşit ve hatlarının verim ve tarımsal özelliklerinin belirlenmesi. Çukurova Üniversitesi Fen Bilimleri Enstitüsü, 20-1: 29-37. 